\title{
Single Beat PR Interval
}

National Cancer Institute

\section{Source}

National Cancer Institute. Single Beat PR Interval. NCI Thesaurus. Code C117774.

An electrocardiographic interval measured from the onset of the $P$ wave to the onset of the QRS complex of a single beat utilizing one or more leads. (CDISC) 